\title{
Lei no 13.466/2017 e a alteração do estatuto do idoso: uma contradição ao rol de prioridade especial para pessoas com mais de 80 anos
}

Law 13.466 / 2017 and the amendment of the Statute of the Elderly: a contradiction to the special priorities for people over 80 years old

Ley 13.466 / 2017 y la modificación del Estatuto de los Ancianos: una contradicción a las prioridades especiales para personas mayores de 80 años

RESUMO. Objetivo: Analisar a alteração legislativa do Estatuto do Idoso realizada pela Lei no 13.466, de 12 de julho de 2017 ao rol de prioridades especiais concedidas a pessoas com mais de 80 anos. Metodologia: Tratou-se de estudo descritivo e analítico, de abordagem qualitativa e revisão bibliográfica sobre a legislação do idoso. Resultados: $A$ análise da legislação permitiu constatar um conflito aparente entre normas legais referente a ordem de atendimento prioritário em saúde para as pessoas idosas. Conclusão: A lei posterior revogou a lei anterior sobre a fila de atendimento emergencial e que as pessoas de 80 anos, a partir da vigência da lei, tem prioridade no atendimento, mesmo que não apresentando risco grave para a saúde.

Palavras-chave: Envelhecimento. Idoso. Direito à saúde. Legislação como Assunto.

ABSTRACT. Objective: To analyze the legislative amendment of the Statute of the elderly performed by law 13.466 of $2017 / 07 / 12$, to the specials priorities granted to the elderly people over 80 years old. Methodology: It was a descriptive-analytical research, with qualitative approach and literature review of the legislation on the elderly population. Results: The analysis of the legislation showed an apparent conflict between legal norms regarding to priority order health care for the elderly population. Conclusion: The subsequent law revoked the previous law on the emergency service queue and the people with 80-year-olds, as of the time of the law, have priority in care, even if they do not present a serious risk to health.

Keywords: Aging. Aged. Right of health. Legislation as Topic.

RESUMEN. Objetivo: Analizar la modificación legislativa del Estatuto del Anciano realizada por la Ley no 13.466, de 12 de julio de 2017, al las prioridades especiales concedidas a personas mayores de 80 años. Metodología: Se trató de estudio descriptivo y analítico, de abordaje cualitativo y revisión bibliográfica sobre la legislación del anciano. Resultados: El análisis de la legislación permitió constatar un conflicto aparente entre normas legales referentes al orden de atención prioritario en salud para las personas mayores de 80 años. Conclusión: La ley subsiguiente revocó la ley anterior sobre la cola del servicio de emergencia y las personas con 80 años de edad, en el momento de la ley, tienen prioridad en la atención, incluso si no presentan un riesgo grave para la salud.

Palabras-Ilave: Envejecimiento. Anciano. Derecho a la salud. Legislación como Asunto.

\footnotetext{
${ }^{1}$ Advogada. Especialista em Direito Público pela Faculdade de Direito Processus. Servidora Pública da Secretaria de Estado de Saúde do Distrito Federal atuante no Posto Avançado da Subsecretaria de Segurança e Saúde no Trabalho do DF - SUBSAUDE/SEPLAG. Email: cristianedocarmo.lima@gmail.com
} 


\section{Introdução}

Envelhecer é uma condição inerente e inevitável a qualquer ser vive. Todo indivíduo, tem total consciência que envelhece a cada dia que se passa, apesar da sociedade desenvolver novas tecnologias no sentido de retardar ao máximo esse evento. Nas palavras de Bourdieu, "a fronteira entre a juventude velhice é objeto de lutas em todas as sociedades". (1)

O conceito de idoso é diferenciado para países em desenvolvimento e para países desenvolvidos. Nos primeiros, são consideradas idosas aquelas pessoas com 60 anos ou mais; nos segundos são idosas as pessoas com 65 anos ou mais. Essa definição foi estabelecida, por meio da Resolução no 39/125 (2), durante a Primeira Assembléia Mundial das Nações Unidas sobre o Envelhecimento da População.

O Brasil envelhece de forma rápida e intensa. Atualmente, o país possui a quinta maior população idosa do mundo. Segundo o Instituto Brasileiro de Geografia e Estatística (IBGE), hoje a população idosa brasileira é composta por 28 milhões de pessoas com 60 anos ou mais, totalizando $13,7 \%$ da população total do país. A expectativa de vida, para ambos os sexos, aumentou para 74 anos, sendo 77,7 anos para a mulher e 70,6 para o homem (3).

Esse crescimento representa uma importante conquista social e resulta da melhoria das condições de vida, com ampliação do acesso a serviços médicos preventivos e curativos, avanço da tecnologia médica, ampliação da cobertura de saneamento básico, aumento da escolaridade e da renda, entre outros determinantes. O grupo dos denominados "mais idosos, muito idosos ou idosos em velhice avançada" (acima de 80 anos), também vêm aumentando proporcionalmente e de maneira mais acelerada, constituindo o segmento populacional que mais cresce nos últimos tempos, sendo hoje mais de $12 \%$ da população idosa. (4)

A preocupação e o interesse público com a velhice foram elevados ao nível constitucional, pois é justamente nesse extremo da vida que o corpo humano se apresenta mais frágil e a pessoa idosa já não dispõe do vigor necessário para enfrentar os dissabores da vida. (5)

A saúde é um estado de completo bem-estar físico, mental e social e não apenas a ausência de doenças e enfermidades (6), também reconhecida como um dos direitos fundamentais de todo ser humano seja qual sua condição social ou econômica e sua crença 
religiosa ou política e inspirado nessa premissa é que o direito à saúde, como um direito social, passou a integrar o texto constitucional nos seguintes termos:

art. 60 São direitos sociais a educação, a saúde, a alimentação, o trabalho, a moradia, o transporte, o lazer, a segurança, a previdência social, a proteção à maternidade e à infância, a assistência aos desamparados, na forma desta Constituição. (Redação dada pela EC no 90/2015) (7)

Nesta corrente de ideais sociais e com ênfase no idoso é que a Lei no 10.741/2003 (8), conhecida como o Estatuto do Idoso, foi publicada reafirmando os ditames constitucionais direcionados aos mais vividos, bem como ao estabelecer novos direitos e aplicação de sanções para alguma possível lesão a tais garantias, bem como adotou o parâmetro de 60 anos para definir a pessoa idosa.

O benefício de atendimento preferencial às pessoas idosas é assegurar ao idoso, com absoluta prioridade, a efetivação do direito à saúde garantindo-Ihe atenção integral à saúde do idoso, por intermédio do Sistema Único de Saúde (SUS), além do acesso universal e igualitário, em conjunto articulado e contínuo das ações e serviços, para a prevenção, promoção, proteção e recuperação da saúde, incluindo a atenção especial às doenças que afetam preferencialmente os idosos. (8)

A finalidade primordial da Portaria MS no 2.528/2006 que aprovou a Política Nacional de Saúde da Pessoa Idosa (9) é recuperar, manter e promover a autonomia e a independência dos indivíduos idosos, direcionando medidas coletivas e individuais de saúde.

De outro lado, o Ministério da Saúde fez publicar a Portaria nำ1.600 em 7 de julho de 2011(10), que reformulou a Política Nacional de Atenção às Urgências (11) e instituiu a Rede de Atenção às Urgências no SUS, como se destaca o $3^{\circ}$ do artigo $3^{\circ}$ do dispositivo:

(...)

art. $3^{\circ}$ Fica organizada, no âmbito do SUS, a Rede de Atenção às Urgências.

(...)

$\S 3^{\circ} \mathrm{O}$ acolhimento com classificação do risco, a qualidade e a resolutividade na atenção constituem a base do processo e dos fluxos assistenciais de toda Rede de Atenção às Urgências e devem ser requisitos de todos os pontos de atenção. (10) 
Em 2004, a Cartilha da Política Nacional de Humanização-PNH (12), aponta o acolhimento nas urgências e emergências com avaliação e classificação de risco, como dispositivo de mudança no trabalho da atenção e produção de saúde. Esse processo dinâmico de identificação de pacientes que necessitam de tratamento imediato, de acordo com o potencial de risco, os agravos à saúde ou o grau de sofrimento, devendo o atendimento ser priorizado de acordo com a gravidade clínica do paciente, e não com a ordem de chegada ao serviço. (13)

Figura 1 - Figura que representa o acolhimento por classificação de risco nas urgências e emergências no Brasil

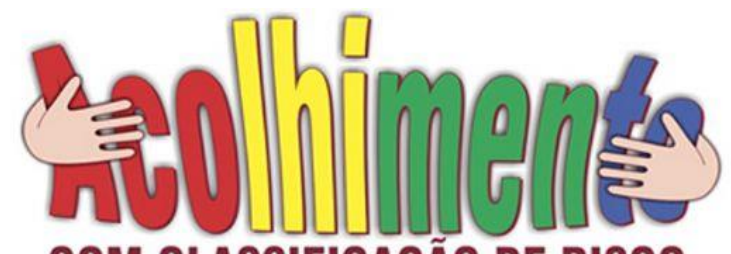

\section{COM CLASSIFICAÇÃO DE RISCO}

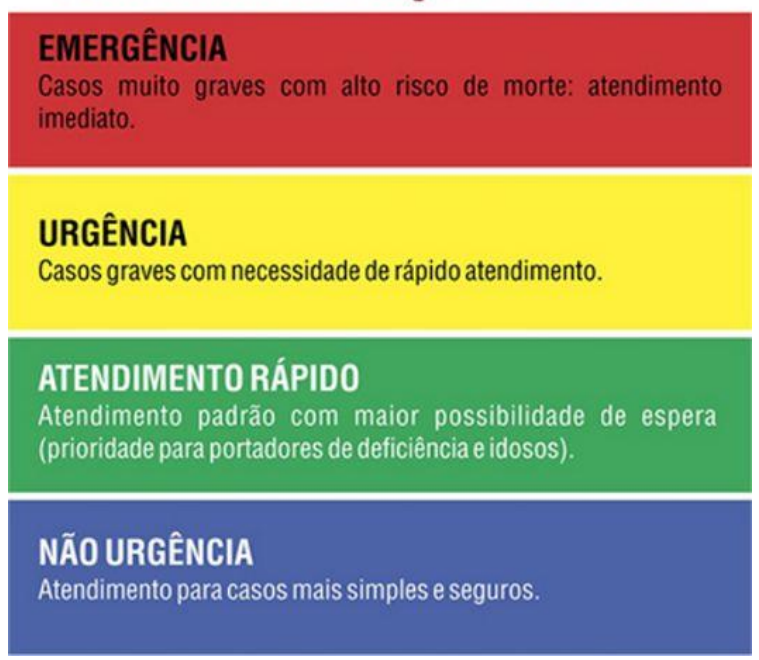

Fonte: Figura representativa do acolhimento por classificação de risco (www.google.com)

A adoção desse sistema, deixou no passado a regra de atendimento aos pacientes segundo a ordem de chegada, o que ocasionava sérios problemas para aqueles que estavam mais graves. Assim, esta ferramenta auxilia na identificação dos pacientes que merecem ser atendidos prioritariamente usando-se critérios, de acordo com a gravidade clínica ou grau de sofrimento. 
Em 12 de julho de 2017, a Lei no 13.466/2017 (14) entrou em vigor, concedendo tratamento diferenciado no SUS para a parcela da sociedade com mais de 80 anos embora, os idosos no Brasil já haviam sido protegidos pela Lei no 10.741/2003 (8).

A partir do novo dispositivo legal, parcela da população passou a obter benefícios extraordinários para além daqueles garantidos no Estatuto do Idoso, em especial o atendimento prioritário nos serviços de saúde.

Deste modo, entende-se haver estabelecido um conflito aparente de normas sobre a ordem de atendimento nos serviços de urgência e emergência do SUS, porque se a ordem hierárquica se dá pela gravidade do quadro do paciente ao chegar ao serviço de saúde, em se tratando de idosos com mais de 80 anos, esta regra estaria revogada?

É o que este artigo tem o escopo de discutir, essa aparente contradição ao rol de prioridades especiais para as pessoas com mais de 80 anos, por meio de um conflito de normas sobre o critério de prioridade no atendimento aos serviços de urgência e emergência em saúde para a população idosa.

\section{Metodologia}

Tratou-se de um estudo descritivo e analítico, com abordagem qualitativa ${ }^{2}$ e uso de técnicas de pesquisa legislativo-documental, por meio da revisão bibliográfica com pertinência ao tema da população idosa no Brasil.

A coleta de dados bibliográficos foi realizada na Biblioteca Virtual em Saúde (BVS), Lilacs (Literatura Latino Americana e do Caribe em Ciências da Saúde), SciELO (Scientific Eletronic Library Online), no Google Acadêmico, site do Ministério da Saúde e LexML, bem como aos acervos bibliográficos no período entre maio a novembro de 2017.

A pesquisa utilizou como descritores os termos "idoso" AND "saúde", " direito" AND " idoso", "idoso de 80 anos ou mais" AND " atendimento de urgência".
A
base
de
dados
do
Ministério
da
Saúde

(http://portalsaude.saude.gov.br/index.php/profissional-e-gestor/legislacao) disponibilizou as Portarias Regulamentadoras da Politica Nacional de Atenção às Urgências, seu

\footnotetext{
2 Por pesquisa qualitativa entende-se como o método de investigação científica que se foca no caráter subjetivo do objeto analisado, voltada para os aspectos qualitativos de uma determinada questão. Isto significa que ela é capaz de identificar e analisar dados que não podem ser mensurados numericamente.
} 
regulamento técnico, o Pacto pela Vida, Política Nacional à Saúde da Pessoa Idosa, bem como as edições de outros documentos com referência na matéria.

A base de dados do LexML proporcionou o estudo da legislação pertinente à população idosa no Brasil, como as Leis n 8.842, de 4 de janeiro de 1994, no 10.741, de 1․ de outubro de 2003 e Lei no 13.466, de 07 de julho de 2017; e o Decreto № 1.948, de 3 de Julho de 1996, dentre outras.

A análise das referências baseou-se, primordialmente, nas publicações dos últimos cinco anos (2012 a 2017) em virtude da atualidade do tema proposto, bem como no conjunto legal de políticas para a população idosa. Posteriormente, houve a pesquisa de autores mais clássicos, o que culminou na ampliação do lapso temporal da pesquisa de cinco anos.

Fez-se uma leitura hermenêutica ${ }^{3}$ da documentação legislativa, o cruzamento e o confronto das fontes foi operação básica, já que possibilitou uma leitura real, contextualizada entre as fontes.

A primeira leitura dos documentos teve a finalidade de verificar adequação aos descritores acima transcritos. Vários documentos disponíveis em websites encontraram pertinência ao estudo. A escolha dos textos não obedeceu nenhuma ordem subsequente à utlização dos descritores. Nos eventos de repetição de textos, houve o descarte destes e posteriormente, realizou-se a leitura e novo filtro para o afunilamento da leitura.

\section{Resultados}

Foram encontradas 21 normas legais e episódios nacionais e internacionais sobre o tema objeto do estudo, que a seguir se encontram organizados no quadro 1.

Quadro 1 - Marcos históricos e legislativos referentes à população idosa

\begin{tabular}{c|l}
\hline Ano & \multicolumn{1}{c}{ Marco histórico legislativo } \\
\hline 1974 & $\begin{array}{l}\text { Lei no 6.179/1974. Foi criada a Renda Mensal Vitalícia, através do então Instituto Nacional } \\
\text { de Previdência Social - INPS, e de decretos, leis, portarias, referentes, principalmente, à } \\
\text { aposentadoria. Institutiu o amparo previdenciário para os maiores de setenta anos e para } \\
\text { os inválidos. }\end{array}$ \\
\hline 1977 & $\begin{array}{l}\text { Lei no 6.439/1977. Foi criado o Sistema Nacional de Previdência e Assistência Social } \\
\text { (SINPAS), integrando: o Instituto Nacional de Previdência Social - INPS, o Instituto } \\
\text { Nacional de Assistência Médica da Previdência Social - INAMPS, a Fundação Legião }\end{array}$
\end{tabular}

\footnotetext{
${ }^{3}$ A hermenêutica é uma arte que visa ao indispensável entendimento da lei, formada de regras técnicas próprias, que variam da simples ao complexo, desde a indagação do intérprete quanto à vontade legislativa através dos termos escritos em que é redigida a norma, até as investigações sociológicas mais profundas. (15)
} 
Brasileira de Assistência - LBA, a Fundação Nacional do Bem-Estar do Menor FUNABEM, a Empresa de Processamento de Dados da Previdência Social DATAPREV, o Instituto de Administração Financeira da Previdência e Assistência Social - IAPAS, para unificar a assistência previdenciária. A inovação para a população idosa foi a manutenção da concessão dos benefícios dos programas de amparo financeiro a idosos e inválidos, abrangendo as prestações em dinheiro devidas na forma da Lei no 6.179, de 11 de dezembro de 1974.

I Assembleia Mundial sobre o Envelhecimento (ONU), em Viena, que traçou as diretrizes

1982 do Plano de Ação Mundial sobre o Envelhecimento, publicado em Nova York em 1983, que almejou sensibilizar o mundo todo para a necessidade de direcionar políticas públicas voltadas para os idosos.

1986 8aㅡ Conferência Nacional de Saúde que propôs a elaboração de uma política global de assistência à população idosa.

Constituição da República Federativa do Brasil de 1988. Destacou no texto constitucional

1988 a referência ao idoso. A família, a sociedade e o Estado têm o dever de amparar as pessoas idosas, assegurando sua participação na comunidade, defendendo sua dignidade e bem-estar e garantindo-lhe o direito à vida.

Lei no 8742/93. a Lei Orgânica de Assistência Social - LOAS. Cita o benefício de

1993 prestação continuada, previsto no art. 20 que é a garantia de um salário mínimo mensal à pessoa portadora de deficiência e ao idoso com setenta anos ou mais e que comprovem não possuir meios de prover a própria manutenção e nem de tê-la provida por sua família.

Lei $\mathrm{n}^{0}$ 8.842/1994. Estabelece a Política Nacional do Idoso (PNI) e cria o Conselho Nacional do Idoso. Estipula o limite de 60 anos e mais, de idade, para uma pessoa ser considerada idosa. A Lei em discussão rege-se por determinados princípios, tais como: assegurar ao idoso todos os direitos de cidadania, com a família, a sociedade e o Estado os responsáveis em garantir sua participação na comunidade, defender sua dignidade, bem-estar e direito à vida.

Política Nacional da Saúde do Idoso que estabelece as diretrizes essenciais que norteiam a definição ou a redefinição dos programas, planos, projetos e atividades do setor na atenção integral às pessoas em processo de envelhecimento e à população idosa. Essas

1999 diretrizes são: a promoção do envelhecimento saudável, a prevenção de doenças, a manutenção da capacidade funcional, a assistência às necessidades de saúde dos idosos, à reabilitação da capacidade funcional comprometida, a capacitação de recursos humanos, o apoio ao desenvolvimento de cuidados informais, e o apoio aos estudos e pesquisas, dentre outras diretrizes.

A Lei $n^{0}$ 10.048/2000. Dá prioridade de atendimento às pessoas idosas, e dá outras providências. As pessoas com deficiência, os idosos com idade igual ou superior a 60 (sessenta) anos, as gestantes, as lactantes, as pessoas com crianças de colo e os

2000 obesos terão atendimento prioritário. As repartições públicas e empresas concessionárias de serviços públicos estão obrigadas a dispensar atendimento prioritário, por meio de serviços individualizados que assegurem tratamento diferenciado e atendimento imediato às pessoas mencionadas.

II Assembleia Mundial sobre Envelhecimento em Madrid - Plano Internacional do Envelhecimento - que tinha o objetivo de servir de orientação às medidas normativas 2002 sobre o envelhecimento no século XXI e fundamentado em três princípios básicos: 1) participação ativa dos idosos na sociedade, no desenvolvimento, na força de trabalho e na erradicação da pobreza; 2) promoção da saúde e bem-estar na velhice; e 3) criação de um ambiente propício e favorável ao envelhecimento.

2003 Conferência Regional Intergovernamental sobre Envelhecimento da América Latina e Caribe, no Chile, na qual foram elaboradas as estratégias regionais para implantar as metas e objetivos acordados em Madrid. $\mathrm{Na}$ área da saúde, a meta geral foi oferecer 
acesso aos serviços de saúde integrais e adequados à necessidade do idoso, de forma a garantir melhor qualidade de vida com manutenção da funcionalidade e da autonomia. Lei $\mathrm{n}^{0}$ 10.741/2003, que aprova o Estatuto do Idoso (6), destinado a regular os direitos assegurados aos idosos. Esse é um dos principais instrumentos de direito do idoso. Sua aprovação representou um passo importante da legislação brasileira no contexto de sua 2003 adequação às orientações do Plano de Madri, pois reafirmou os ditames constitucionais direcionados aos mais vividos, bem como estabeleceu novos direitos e aplicação de sanções para alguma possível lesão a tais garantias. $O$ estatuto concedeu ainda, tratamento personalíssimo ao envelhecimento e classificou como direito fundamental à vida e fixou sua proteção com caráter social.

\begin{tabular}{|c|c|}
\hline 2004 & $\begin{array}{l}\text { Decreto no } 5.109 / 2004 \text {. Dispõe sobre a composição, estruturação, competências e } \\
\text { funcionamento do Conselho Nacional dos Direitos do Idoso (CNDI) e dá outras } \\
\text { providências. }\end{array}$ \\
\hline 2006 & $\begin{array}{l}\text { I Conferência Nacional dos Direitos da Pessoa ldosa, na qual foram aprovadas diversas } \\
\text { deliberações, divididas em eixos temáticos, que visou garantir e ampliar os direitos da } \\
\text { pessoa idosa e construir a Rede Nacional de Proteção e Defesa da Pessoa Idosa - } \\
\text { RENADI. }\end{array}$ \\
\hline 2006 & $\begin{array}{l}\text { Portaria no 2.528/2006. Aprova a Política Nacional de Saúde da Pessoa Idosa. Essa } \\
\text { política tem como principais diretrizes: envelhecimento ativo e saudável, atenção integral } \\
\text { e integrada à saúde da pessoa idosa, estimulo às ações intersetoriais, além do } \\
\text { fortalecimento do controle social, garantia de orçamento, incentivo a estudos e pesquisas } \\
\text { dentre outras. }\end{array}$ \\
\hline 2006 & Lei no 11.433/2006. Dispõe sobre o Dia Nacional do Idoso. \\
\hline 2007 & Lei no 11.551/2007. Institui o Programa Disque Idoso. \\
\hline 2008 & $\begin{array}{l}\text { Lei } n^{\circ}=11.765 / 2008 \text {. Acrescenta inciso ao parágrafo único do art. 3o da Lei no } 10.741 \text {, de } \\
\text { 1o de outubro de } 2003 \text { - Estatuto do Idoso, para dar prioridade ao idoso no recebimento } \\
\text { da restituição do Imposto de Renda. }\end{array}$ \\
\hline 2009 & $\begin{array}{l}\text { Lei no } 12.008 / 2009 \text {. Prioridade na Tramitação de Processos "Judiciais" e Procedimentos } \\
\text { Administrativos. Idosos e Portadores de Doenças Graves. }\end{array}$ \\
\hline 2010 & $\begin{array}{l}\text { Lei } \mathrm{n}^{0} \text { 12.213/2010. Institui o Fundo Nacional do Idoso, que autoriza a dedução do } \\
\text { imposto de renda a pessoas físicas e jurídicas que realizarem doações ao referido fundo. }\end{array}$ \\
\hline 2017 & $\begin{array}{l}\text { Lei } n^{\circ} 13.466 / 2017 \text {. Altera os arts. } 3^{\circ}, 15 \text { e } 71 \text { da Lei } n^{\circ} 10.741 \text {, de } 1^{\circ} \text { de outubro de } \\
2003 \text {, que dispõe sobre o Estatuto do Idoso e dá outras providências, a fim de } \\
\text { estabelecer a prioridade especial das pessoas maiores de oitenta anos. }\end{array}$ \\
\hline
\end{tabular}

Fonte: Elaboração própria, a partir do site da Presidência da República. http://www2.planalto.gov.br/acervo/legislacao.

O atendimento preferencial da população idosa é tratado em dois dispositivos legais: a Lei no 10.741/2003 (8) que disciplina o atendimento preferencial de saúde às pessoas com mais de 60 anos de idade e a Lei no 13.466/2017 (14) que dá prioridade especial para as pessoas com mais de 80 anos. No arcabouço infralegal, o Ministério da Saúde instituiu a Rede de Atenção às Urgências no SUS (10) e a Cartilha da Política Nacional de Humanização (12), enquanto em nível internacional, foi editado o Protocolo de Manchester 
${ }^{4}(16)$, todos dispositivos diretamente relacionados a ordem de atendimento emergencial de saúde.

Cabe considerar que a Rede de Atenção às Urgências foi expedida pela Portaria do Ministério da Saúde no 1.600/2011(10). Dentro do ordenamento jurídico brasileiro, as portarias são atos administrativos com hierarquia inferior às leis federais. Neste sentido, os ditames estabelecidos em portaria não podem contrariar ou modificar normas contidas em texto regulamentar anterior, como o de lei federal. Neste sentido o jurista J. Cretella Júnior, traz seus ensinamentos sobre o valor jurídico da portaria:

No Direito Administrativo, portarias são documentos de ato administrativo de qualquer autoridade pública, que contém instruções acerca da aplicação de leis ou regulamentos, recomendações de caráter geral, normas de execução de serviço, nomeações, demissões, punições, ou qualquer outra determinação de sua competência.

A portaria não pode contrariar princípios gerais do direito, como o da igualdade de todos perante a lei; não pode criar situações de privilégio entre aqueles aos quais se dirige, funcionários ou administrados; não pode encerrar qualquer dispositivo de caráter particular, conflitante com dispositivo paralelo do diploma anterior ao qual se refere; não pode ab-rogar ou modificar normas contidas no texto básico dinamizado; não pode criar direitos novos ou obrigações novas, não estabelecidos no texto básico; não pode ordenar ou proibir o que o texto fundamental ordena, ou não proíbe; não pode facultar, ou proibir diversamente do que o texto básico estabelece.

(...)

Sempre que órgão administrativo baixa ou expede portaria sobre matéria já disciplinada em texto genérico anterior (lei, decreto, regulamento), cumpre indagar a respeito da adequação perfeita da portaria ao texto básico anterior, porque, sendo a portaria uma particularização ou desenvolvimento de um dispositivo ou de uma série de dispositivos, em vigor, será ilegal e, portanto, inaplicável, a disposição da portaria que conflite com o comando a que reporta. Onde a portaria fere de modo frontal a lei, o regulamento, o decreto, o intérprete concluirá, de imediato, por sua ilegalidade. Onde a portaria inova, criando, inaugurando regime jurídico disciplinador de um instituto, é ilegal e, pois, suscetível de censura jurisdicional(17).

Neste contexto, a realidade dos atendimentos emergenciais de saúde no Brasil, é baseada em regras expedidas por uma portaria do Ministério da Saúde que não obedecem

\footnotetext{
${ }^{4}$ O Protocolo de Manchester é um sistema de classificação de risco que inicialmente foi implantado no Manchester Royal Infirmary na cidade de Manchester, em 1997, permite a identificação da prioridade clínica e a definição do tempo alvo recomendado até a avaliação médica, quer em situações de funcionamento normal do serviço de urgência, quer em situações de catástrofe ou múltiplas vítimas. O Protocolo de Manchester é baseado em categorias de sinais e sintomas e contêm 52 fluxogramas (sendo 50 utilizados para situações rotineiras e dois para situação de múltiplas vítimas) que serão selecionados a partir da situação/queixa apresentada pelo paciente. Cada fluxograma contem discriminadores que orientarão a coleta e análise de informações para a definição da prioridade clínica do paciente. O Sistema Manchester pretende assegurar que a atenção médica ocorra de acordo com o tempo resposta determinado pela gravidade clínica do paciente, além de ser ferramenta importante para o manejo seguro dos fluxos dos pacientes quando a demanda excede a capacidade de resposta.
} 
os preceitos exarados anteriormente por lei federal, especificamente, à população idosa, como é o caso da Lei no 10.741/2003 (8), o Estatuto do Idoso, no qual disciplina o atendimento preferencial, imediato e individualizado com absoluta prioridade aos serviços de saúde do país, na contramão do texto da portaria que adota uma classificação de risco com base no estado físico do paciente.

A edição da Lei no 13.466/2017 (14) veio a criar uma contradição ao rol de benefícios de atendimento prioritário nas emergências, aos idosos do Brasil, uma vez que já existem comandos detalhados, claros e sem lacunas para interpretações em sentido contrário sobre a matéria. Dessa forma, os idosos com mais de 80 anos, terão uma prioridade maior, exceto nos atendimentos emergenciais de saúde.

Assim, configura-se um conflito aparente de normas quando, segundo Kelsen (18) há uma incompatibilidade entre o que é fixado como devido por uma norma e o que outra norma estabelece. Uma das formas de conflitos de normas é chamada de antinomia ${ }^{5}$ jurídica, que é definida como uma situação de coexistência de normas jurídicas de mesma hierarquia, focadas no mesmo assunto, todavia, com posicionamentos diferentes, como bem leciona Caio Mário da Silva Pereira:

Dá-se o nome de antinomia à situação em que se mostram incompatíveis duas ou mais normas jurídicas. Se um dispositivo legal obriga certa conduta e outro proíbe a mesma conduta, está-se diante de um exemplo de antinomia. (...)

As antinomias devem ser superadas. A segurança que o direito positivo deve inspirar nas pessoas sujeitas às suas regras de conduta pressupõe a existência de critérios para a eliminação das antinomias. Uma das normas incompatíveis deve prevalecer sobre a outra (20).

Critérios de solução de conflitos de normas são os pontos de partida que são tomados como base para encontrar dentre as possibilidades existentes de normas aplicáveis a um caso ou a casos semelhantes entre si, qual é a norma a ser usada. Situações de conflito de normas são solucionadas através da aplicação de três critérios: hierárquico, cronológico e da especialidade (21).

No critério hierárquico (lex superior derogat legi inferiori) não há o que se falar em norma jurídica inferior contrária à superior, uma vez que "a norma que representa o

\footnotetext{
${ }^{5} \mathrm{Na}$ tradição cética ou em doutrinas influenciadas pelo ceticismo, tal como o kantismo, contradição entre duas proposições filosóficas igualmente críveis, lógicas ou coerentes, mas que chegam a conclusões diametralmente opostas, demonstrando os limites cognitivos ou as contradições inerentes ao intelecto humano. Em termos jurídicos, antinomia significa contradição real ou aparente entre leis, ou entre disposições de uma mesma lei, o que dificulta sua interpretação. (19)
} 
fundamento de validade de uma outra norma é, em face desta, uma norma superior". (22) Um bom exemplo deste critério é o da Constituição Federal de 1988 que tem caráter supralegal, na qual, as demais leis devem estar em consonância aos princípios estabelecidos por ela, caso contrário será considerada inconstitucional perdendo sua efetividade.

O segundo critério é o cronológico (lex posterior derogat legi priori). Este, tem por fundamento no artigo $2^{\circ}$ da Lei de Introdução às Normas do Direito Brasileiro (22), no qual, não se destinando à vigência temporária, a lei terá vigor até que outra a modifique ou revogue, bem como no seu $\S^{1} \stackrel{0}{ }$ no qual disciplina que norma posterior revoga a anterior: "a lei posterior revoga a anterior quando expressamente o declare, quando seja com ela incompatível ou quando regule inteiramente a matéria de que tratava a lei anterior."

Por derradeiro, o critério da especialidade (lex specialis derogat legi generali) dispõe que a norma especial prevalece sobre a geral, ou seja, "a lei nova, que estabeleça disposições gerais ou especiais a par das já existentes, não revoga nem modifica a lei anterior". (22)

Aplicando-se a teoria ao questionamento do estudo, tem-se o quadro comparativo estabelecido no quadro 2.

Quadro 2 - Quadro comparativo entre o Estatuto do Idoso(08), a Lei № 13.466/2017(15) no que se refere a preferência de atendimento

\section{Lei $\mathrm{n}^{0} 10.741 / 2003$}

Dispõe sobre o Estatuto do Idoso e dá outras providências

Art. $2^{\circ}$, $\mathrm{O}$ idoso goza de todos os direitos fundamentais inerentes à pessoa humana, sem prejuízo da proteção integral de que trata esta Lei, (...).

Art. 3으 (...) e do Poder Público assegurar ao idoso, com absoluta prioridade, a efetivação do direito à vida, à saúde, (...).

Parágrafo único. A garantia de prioridade compreende:

I - Atendimento preferencial imediato e individualizado junto aos órgãos públicos e privados prestadores de serviços à população.

Art. 15. É assegurada a atenção integral à saúde do idoso, por intermédio do Sistema Único de Saúde -

Lei no 13.466/2017

Altera o Estatuto do Idoso ao estabelecer a prioridade especial das pessoas maiores de oitenta anos.

Art. $1^{\circ}$ Esta Lei altera os arts. $3^{\circ}, 15$ e 71 da Lei $n^{\circ} 10.741,(\ldots)$, a fim de estabelecer a prioridade especial das pessoas maiores de oitenta anos.

Art. $2^{\circ} \mathrm{O}$ art. $3^{\circ}$ da Lei $n^{\circ} 10.741$, de $1^{\circ}$ de outubro de 2003, passa a vigorar acrescido do seguinte:

(...)

$\S 2^{\circ}$ Dentre os idosos, é assegurada prioridade especial aos maiores de oitenta anos, atendendo se suas necessidades sempre preferencialmente em relação aos demais idosos." (NR) 
SUS, garantindo-Ihe o acesso universal e igualitário, (...).

Art. 18. As instituições de saúde devem atender aos critérios mínimos para 0 atendimento às necessidades do idoso, promovendo o treinamento e a capacitação dos profissionais, assim como orientação a cuidadores familiares e grupos de autoajuda.
Art. $3^{\circ} \mathrm{O}$ art. 15 da Lei $\mathrm{n}^{\circ} 10.741$, de $1^{\circ}$ de outubro de 2003, passa a vigorar acrescido do seguinte:

(...)

$\S 7^{\circ} \mathrm{Em}$ todo atendimento de saúde, os maiores de oitenta anos terão preferência especial sobre os demais idosos, exceto em caso de emergência." (NR)

Fonte: Elaborado pela autora a partir do Estatuto do Idoso e da Lei ํo 13.466/2017.

Neste contexto, tem-se a situação de normas legais federais disciplinando sobre a concessão de atendimento prioritário à população idosa de maneira conflitante.

O Estatuto do Idoso concede um atendimento preferencial imediato e individualizado, com absoluta prioridade para as pessoas idosas, sem distinção de idade e com atenção integral a fim de alcançar a efetivação do direito à saúde dessa parcela da população. Enquanto a Lei no 13.466/2017(14) faz menção em estabelecer prioridade especial às pessoas com mais de 80 anos em atendimento de serviços de saúde, exceto nas emergências.

No estatuto do idoso não existia essa exceção aos atendimentos nas emergencias e a Lei $n^{\circ} 13.466 / 2017$ (14) que veio conceder uma super prioridade aos idosos com mais de 80 anos, mas retira do contexto de direitos garantidos anteriormente aos idosos, independentemente da idade, a prioridade de atendimento imediato e individualizado nas urgências e emergências do país. Na tentativa de sistematizar a situação a pouco descrita, o esbouço que se apresenta é o seguinte:

Figura 3 - Figura ilustrativa das divergências entre a Lei no 10.741/2003(8), o Estatuto do Idoso e a Lei no 13.466/2017 (15).
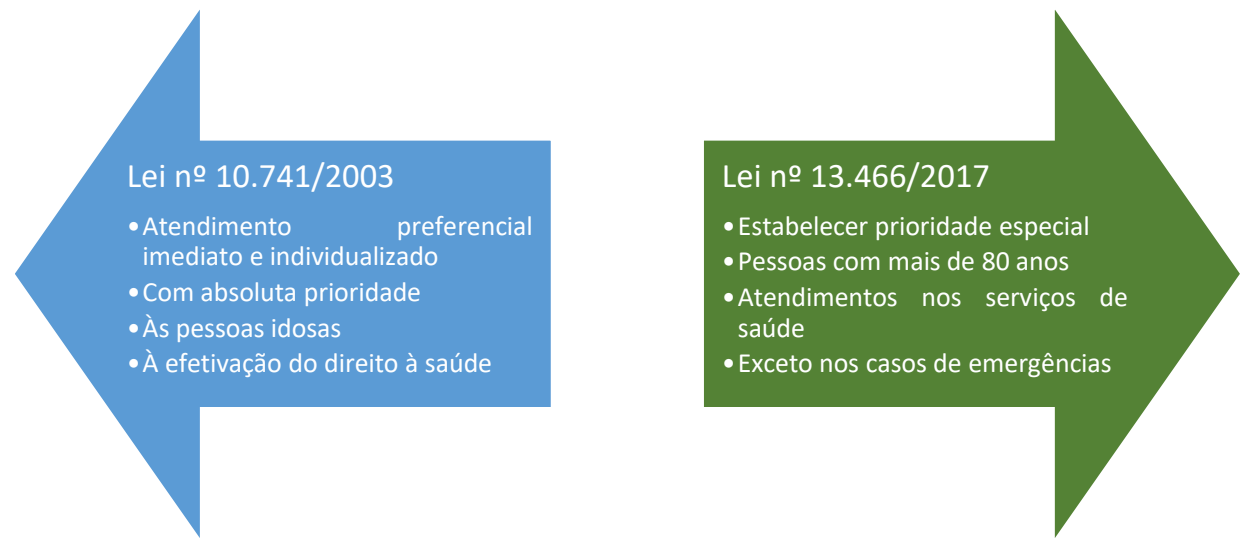

Fonte: Elaborado pela autora a partir do Estatuto do Idoso e da Lei ํㅜ 13.466/2017. 
Neste contexto, tem-se a situação de normas legais federais disciplinando sobre a concessão de atendimento prioritário à população idosa nos serviços emergenciais de saúde.

\section{Considerações finais}

É inegável que a população mundial está envelhecendo e as expectativas apontam, para um número a cada vez mais crescente de idosos no mundo. Esta realidade repete-se igualmente no Brasil.

O atendimento prioritário em saúde à pessoa idosa é um direito legalmente constituído. Porém, dada a complexidade dos serviços oferecidos no contexto hospitalar e a elevada demanda por atendimento, a idade é estabelecida como um critério especial, mas não o único.

Com a edição do Estatuto do Idoso, esta parcela crescente da sociedade adquiriu o direito fundamental ao atendimento emergencial à saúde, eis que não havia nenhuma ressalva em seu conteúdo que expressasse a exceção às emergências de saúde. Com a edição da Lei no 13.466/2017 houve a concessão de uma super prioridade aos idosos com 80 anos ou mais em vários campos de incidência, sem contudo, beneficiar essa parcela no que se refere aos atendimentos de emergência. Assim, essa super prioridade vem lesionar o direito adquiridos dos mesmos concedidos pelo Estatuto no que se refere às emergências.

Ao se confrontar a realidade das urgências e emergências no Brasil, contata-se que a ordem de atendimento em saúde adotada pela Portaria do Ministério da Saúde que avaliam as prioridades baseadas nos riscos que os pacientes correm, por meio da avaliação e classificação de risco. Sob a ótica médica, o mais importante é o sofrimento e a ocorrência do evento morte a que os pacientes estejam submetidos. Tal perspectiva é clínica e não legal. A prioridade pelo estado do paciente está condicionado pelas legislações existentes e as que os médicos têm que prestar obediência.

Todavia, a população idosa possui tratamento legislativo específico dado pelo Estatuto do Idoso, Lei no 10.741/2003, no que se refere ao atendimento preferencial, imediato e individualizado, com absoluta prioridade e atenção integral em saúde a fim de alcançar a efetivação do direito à saúde dos idosos, alterado pela Lei nº 13.466/2017 que concedeu prioridade especial às pessoas a partir dos 80 anos, ressalvando os serviços de emergência. 
Neste contexto, observou-se a situação de normas legais federais disciplinando sobre a concessão de atendimento prioritário à população idosa de maneira conflitante, no qual uma delas, qual seja, a Lei n 13.466/2017 ocasionou uma redução de direitos à população idosa do país. O atendimento à saúde aos idosos não pode ser precarizado, justamente em um periodo da vida no qual a necessidade de acompanhamnto médico se torna praticamente uma rotina, em virtude do surgimento de doenças que acometem especificamente essa parcela da sociedade. No mundo jurídico existe uma máxima de que não haverá lesão ao ato jurídico perfeito, à coisa julgada e aos direitos adquiridos.

Diante da análise conclui-se que, de acordo com os critérios hierárquico e da especialidade de solução de conflitos aparente de normas, a lei posterior revogou a lei anterior sobre a ordem de atendimento emergencial e que as pessoas de 80 anos, a partir da vigência da lei, tem prioridade no atendimento, mesmo que não apresentando risco grave para a saúde, bem como o fato de a lei nova, que estabelece disposições gerais ou especiais a par das já existentes, não revoga nem modifica a lei anterior.

\section{Referências}

1. Gonçalves FPF, Teixeira JPA. A Administração Pública: o Direito à saúde e a pessoa idosa. In: Leite GS, Mendes GF, Mudrovitsch RB, Leite GS, et al. Manual de direitos da pessoa idosa. São Paulo. Saraiva, 2017.

2. Organização das Nações Unidas. Assembléia Mundial sobre envelhecimento: Resolução no 39/125. ONU: Viena, 1982. Disponível em: https://nacoesunidas.org/acao/pessoas-idosas/ [Acesso em 5.nov.2017].

3. Instituto Brasileiro de Geografia e Estatística. Projeção da População do Brasil por sexo e idade: 2000-2060. Brasília: IBGE, 2013. Disponível em:

ftp://ftp.ibge.gov.br/Projecao da Populacao/Projecao da Populacao 2013/nota metodolo gica 2013.pdf [Acesso em $1^{\circ}$.out.2017].

4 -. $\quad$ Ministério da Saúde. Coordenação da Saúde da Pessoa Idosa. Brasília, 2017. Disponível em: http://u.saude.gov.br/index.php/o-ministerio/principal/secretarias/808-sasraiz/daet-raiz/saude-da-pessoa-idosa/l1-saude-da-pessoa-idosa/12330-apresentacao-spidosa [Acesso em 15.out.2017].

5. Colleti, V. Direito dos idosos nas áreas da saúde e assistencia social: um estudo voltado ao município de Lajeado-RS. 2009. Disponível em: 
https://www.univates.br/media/graduacao/direito/artigo volmir.pdf. [Acesso em 20.set.2017].

6. Organização Mundial da Saúde. Constituição da Organização Mundial da Saúde (OMS/WHO) - 1946. Disponível em: http://www.direitoshumanos.usp.br/index.php/OMSOrganiza\%C3\%A7\%C3\%A3o-Mundial-da-Sa\%C3\%BAde/constituicao-da-organizacaomundial-da-saude-omswho.html [Acesso em 5.dez.2017].

7. Brasil. Constiuição da República Federativa do Brasil. 5 de outubro de 1988. Brasília: Senado Federal, 2015.

8. Ministério da Saúde. Estatuto do idoso. Brasília: Legislação de Saúde, 2007. Disponível em: http://conselho.saude.gov.br/biblioteca/livros/estatuto idoso2edicao.pdf. [Acesso em 18.set.2017].

9. Ministério da Saúde. Portaria GM/MS № 2.528, de 19 de outubro de 2006. Aprova a Politica Nacional de Saúde da Pessoa Idosa. Diário Oficial da União. Brasília. Disponível em: http://bvsms.saude.gov.br/bvs/saudelegis/gm/2006/prt2528 1910 2006.html [Acesso em 6.ago.2017].

10. Ministério da Saúde. Portaria no 1.600, de 7 de julho de 2011. Reformula a Política Nacional de Atenção às Urgências e institui a Rede de Atenção às Urgências no Sistema Único de Saúde (SUS). Diário Oficial da União. Brasília. Disponível em: http://bvsms.saude.gov.br/bvs/saudelegis/gm/2011/prt1600 0707 2011.html. [Acesso em 18.set.2017].

11. Ministério da Saúde. Política Nacional de Atenção às Urgências. Brasília: Ministério da Saúde, 2003. Disponível em:

http://bvsms.saude.gov.br/bvs/publicacoes/politica nac urgencias.pdf [Acesso em 18.set.2017].

12. Ministério da Saúde. Cartilha da Política Nacional de Humanização (PNH). Brasília, 2013. Disponivel em:

http://bvsms.saude.gov.br/bvs/publicacoes/politica nacional humanizacao pnh folheto.pdf [Acesso em 22.set.2017].

13. Abbes C, Massaro A. Acolhimento com avaliação e classificação de risco: um paradigma ético estético no fazer em saúde. In: Roncato PAZB, Roxo CO, Benites DF. Acolhimento com classificação de risco na estratégia de saúde da família. Revista da AMRIGS. 2012; 56(4):308-313. Disponível em: http://www.amrigs.org.br/revista/564/1048.pdf [Acesso em 16.dez.2017].

14. Brasil. Lei no 13.466 , de 12 de julho de 2017. Altera os arts. $3^{\circ}, 15$ e 71 da Lei no 10.741 , de $1^{\circ}$ de outubro de 2003, que dispõe sobre o Estatuto do Idoso e dá providências. Disponível em: http://www.planalto.gov.br/ccivil 03/ ato2015-2018/2017/lei//13466.htm [Acesso em 26.ago.2017]. 
15. Diniz MH. Curso de Direito Civil Brasileiro: teoria geral do direito civil. São Paulo: Saraiva, 2018.

16. Grupo Brasileiro de Classificação de Risco. Protocolo Manchester. Disponível em: http://gbcr.org.br/ [Acesso em 10.out.2017].

17. Júnior JC. Valor jurídico da portaria. Rev. Dir. Adm. 1974; 117:447-459. Disponível em: http://bibliotecadigital.fgv.br/ojs/index.php/rda/article/view/40205/38944. [Acesso em 05.nov.2017].

18. Kelsen H. Teoria Pura do Direito. São Paulo: Editora Revista dos Tribunais, 2014.

19. Baptista MEC. A antinomia pré-socrática - o ser e o devir. Disponível em: http://www.hierophant.com.br/arcano/posts/view/Marina/54 [Acesso em 10.dez.2017].

20. Pereira CMS. Instituições de Direito Civil: introdução ao direito civil - teoria geral do direito civil. São Paulo: Editora Forense, 2017.

21. Bezerra R. Antinomia. O conflito aparente de normas e seus critérios de resolução. Disponível em: https://rodrigobezerraadv.jusbrasil.com.br/artigos/297827324/antinomia-oconflito-aparente-de-normas-e-seus-criterios-de-resolucao [ Acesso em 27.out.2017].

23. Brasil. Decreto-Lei o 4.657 , de 4 de setembro de 1942. Lei de Introdução às Normas do Direito Brasileiro. Disponível em: http://www.planalto.gov.br/ccivil 03/decretolei/Del4657.htm [Acesso em 15.out.2017].

\section{Como citar este artigo:}

Lima CCS. Lei no 13.466/2017 e a alteração do estatuto do idoso: uma contradição ao rol de prioridade especial para pessoas com mais de 80 anos. Revista Cadernos Ibero-Americanos de Direito Sanitário. 2018 jan./mar, 7(1): 147-162. 